\title{
Breast size impact on adjuvant radiotherapy adverse effects and dose parameters in treatment planning
}

\author{
Ivica Ratosa ${ }^{1}$, Aljasa Jenko², Irena Oblak \\ ${ }^{1}$ Division of Radiotherapy, Institute of Oncology Ljubljana, Ljubljana, Slovenia \\ ${ }^{2}$ Division of Radiotherapy, Department of Medical Physics, Institute of Oncology Ljubljana, Ljubljana, Slovenia
}

Radiol Oncol 2018; 52(3): 233-244.

Received 30 March 2018

Approved 12 June 2018

Corresponding author: Assist. Prof. Irena Oblak, M.D., Ph.D., Institute of Oncology Ljubljana, Zaloška cesta 2, 1000 Ljubljana, Slovenia. Phone: +386 15879 661; Fax: +386 15879 304; E-mail: ioblak@onko-i.si

Disclosure: No potential conflicts of interest were disclosed.

Background. Breast radiotherapy is an established adjuvant treatment after breast conserving surgery. One of the important individual factors affecting the final cosmetic outcome after radiation is breast size. The purpose of this review is to summarise the clinical toxicity profile of adjuvant radiotherapy in women with breasts of various sizes, and to evaluate the treatment planning studies comparing target coverage and dose to thoracic organs at risk in relation to breast size.

Conclusions. Inhomogeneity and excessive radiation dose (hot spots) in the planning of target volume as well as large volume of the breast per se, all contribute to a higher rate of acute adverse events and suboptimal final cosmetic outcome in adjuvant breast cancer radiotherapy, regardless of the fractionation schedule. Improved homogeneity leads to a lower rate of $\geq$ grade 2 toxicity and can be achieved with three-dimensional conformal or modulated radiotherapy techniques. There may be an association between body habitus (higher body mass index, bigger breast size, pendulous breast, and large chest wall separation) and a higher mean dose to the ipsilateral lung and whole heart. A combination of the technical innovations (i.e. the breath-hold technique, prone position with or without holding breath, lateral decubitus position, and thermoplastic bra), dose prescription (i.e. moderate hypofractionation), and irradiated volume (i.e. partial breast irradiation) should be tailored to every single patient in clinical practice to mitigate the risk of radiation adverse effects.

Keywords: breast cancer, breast size, radiation side effects, organs at risk, treatment planning

\section{Introduction}

With the ageing population and screening programs adopted worldwide, both the incidence and prevalence of breast cancer (BC) are projected to increase over the next decades. Since radiotherapy is one of the key modalities in BC treatment, the absolute number of new BC patients in need of external beam radiotherapy is expected to increase in the immediate future in nearly all European countries. $^{1}$

Breast conserving surgery in combination with adjuvant radiotherapy has become the standard of care in BC management. ${ }^{2,3}$ Large retrospective population-based studies nowadays show that breast conserving therapy (BCT) may have an even better outcome in terms of BC-specific and overall survival compared to mastectomy. ${ }_{4} \mathrm{BCT}$, when compared to more radical surgery, has a positive impact on the patient's quality of life many years after treatment, especially in terms of body image, sexual activity, and better physical and role functioning. ${ }^{5}$

Clinicians and researches alike are paying particular attention to reducing acute and late treatment toxicities in a growing number of BC survivors. ${ }^{6}$ Acute skin toxicity is very common and 
ranges from mild erythema to moist or dry skin desquamation, with the peak reaction occurring one to two weeks post treatment. ${ }^{7,8}$ Late skin reactions include skin fibrosis, skin dyspigmentation, and telangiectasia. Acute heart or lung toxicities are rarely seen in $\mathrm{BC}$ adjuvant radiation treatment, but late sequelae may be life threatening, with acute coronary event and lung cancer being two possible complications. $^{9}$

Advances in BC radiotherapy - among them being moderate hypofractionation schedule (HF), intensity modulated radiotherapy (IMRT), and prone or lateral decubitus position - have all the potential to reduce the rates of acute and long-term radiotherapy-related side effects of BCT.6,7,10-14 The observed normal tissue toxicity rates and breast cosmetic outcome depend on treatment and patient-related factors such as the type and number of surgical procedures, systemic treatment, breast size and shape, race, age, comorbidities, smoking, individual sensitivity to ionizing radiation, choice of fractionation and radiation dose, skin bolus, inter-fraction time interval, volume irradiated, and radiotherapy delivery modality..$^{15}$ It is a widely accepted fact that patient-related factors, such as higher body mass index (BMI) and larger breasts $7,10,16$ increase the risk of $\geq$ grade 2 (G2) dermatitis, regardless of the fractionation regimen. ${ }^{11,17}$

We conducted a review to summarise the clinical toxicity profile of adjuvant radiotherapy in women with breasts of various sizes, and to assess the dosimetric studies of different treatment planning techniques which compared the target coverage (also related to breast size) and dose to thoracic organs at risk with a focus to cardiac subvolumes.

\section{Materials and methods}

\section{Literature search and selection criteria}

A comprehensive literature search for clinical and dosimetric findings was carried out using PubMed/ Medline from January 1990, with 30 September 2017 being the last search date. Only English literature was considered, using the following key words: "breast cancer" and "radiotherapy". Subheadings were searched with "organ size", "3D-conformal radiotherapy (3D-CRT)", "intensity modulated radiotherapy (IMRT)", "hybrid-IMRT", and "volumetric-modulated arc therapy (VMAT)", "organs at risk", "treatment planning", "Heart/radiation effects", "Coronary Vessels/radiation effects", and "dosimetric comparison". Additional relevant references were found in reference lists published with the articles. Clinical studies were selected independently of the number of the patients included. We also searched for treatment planning studies with at least 2 different treatment modalities (i.e. 3D-CRT, IMRT (multi-beam and tangential), hybrid-IMRT, and volumetric modulated arc therapy (VMAT) for left-sided breast cancer).

All selected articles were reviewed in full-text versions and were further divided into clinical or treatment planning articles. In clinical studies, we searched for acute skin toxicity, heart and lung toxicity, secondary malignancy risk, and for possible strategies to modify the toxicity, again taking into account the different breast size categories. Treatment planning studies were reviewed in detail and selected only if the delineated organs at risk included at least one additional heart substructure, namely coronary arteries or cardiac chambers.

\section{Results}

The aim of the literature search was to select all clinical and treatment planning studies of adjuvant breast radiotherapy, taking into account the different breast size categories. The search retrieved 6074 articles, 5980 of which were excluded from the review because the content of the article did not match the search criteria, the content was irrelevant to the review topic, or the records were duplicated. Ultimately, 94 articles were found relevant to this study.

\section{Definition of small, medium, and large breast volume}

Clinical studies do not define different breast sizes uniformly. Some of the studies differentiate between breast volumes using measures such as clothing and bra size, where a cup size $\geq$ D categorises woman as having large breasts., ${ }^{71}$ In a study by Pignol et al., breast size was defined as follows: small (USA bra sizes 32A/B, 34A/B, and 36A), medium (USA bra sizes 32C, 34C, 36B/C, and 38A/B/C), or large (all other). ${ }^{7}$ Some studies use the distance between the edges of the lateral and medial fields, where a breast separation of approximately 18 and $25 \mathrm{~cm}$ constitutes medium and larger breast sizes, respectively. ${ }^{19}$ Modern three-dimensional treatment planning allows for the target volume to be measured, and clinical target volumes (CTV) of $\geq 1.600 \mathrm{~cm}^{3}, 975-1.600 \mathrm{~cm}^{3}$, and $\leq 500-975 \mathrm{~cm}^{3}$ have been defined as large, medium, and small breasts, respectively. ${ }^{20,21}$ One study described a standard- 
ised and reproducible protocol to measure breast size (the thickness of left and right axillary fat and nipple-to-pectoral muscle distance), finding that anthropometric measurements correlate with the risk of skin toxicity. ${ }^{16}$

\section{Acute toxicity}

Randomised clinical trials and retrospective clinical data from standard tangential two-dimensional radiotherapy with wedges (2D-RT) vs. IMRT show an improvement in planning target volume homogeneity and conformity with IMRT, which may have a clinically significant benefit in reducing the rates of acute dermatitis, moist desquamation, pruritus, palpable breast fibrosis, and acute and chronic oedema in women with all breast sizes., ${ }^{70,22-25} \mathrm{~A}$ detailed investigation about the IMRT technique across the studies revealed different planning approaches. IMRT was partly defined as a manual forward-planned technique (F-IMRT), 10,22,23,25-27 and partly as an inverse algorithm ${ }^{7,23}$, hybrid IMRT $(\text { H-IMRT })^{28}$, and typically used physical compensators and step-and-shoot multi-leaf collimator (MLC) fields ${ }^{7,10,22,23,25,26}$ or enhanced dynamic wedges and dynamic MLCs. ${ }^{29} \mathrm{~A}$ systematic review and meta-analysis of side effects associated with the use of IMRT in adjuvant BC treatment can be found elsewhere. ${ }^{30}$

In 2008, Pignol et al. reported a correlation of increased moist desquamation anywhere in the breast with BMI, increasing breast separation, smaller vs. larger breast sizes, and with a higher relative volume of the breast receiving > 105-115\% of the prescribed dose. ${ }^{7}$ In a multivariate analysis, IMRT was associated with a decreased risk of moist desquamation (odds ratio, OR, 0.418, $\mathrm{p}=0.0034$ ) while breast size (per $\left.100 \mathrm{~cm}^{3}\right)(\mathrm{OR} 1.23, \mathrm{p}<0.0001)$ was associated with an increased risk. ${ }^{7}$ Moist desquamation was also correlated with a reduction in the global health status scale $(\mathrm{p}=0.0019), \geq \mathrm{G} 2$ pain score, and with an increase in the breast symptoms scale $(p=0.0028){ }^{7} \mathrm{G} 2-4$ acute pain was not statistically different between IMRT or conventional radiotherapy arms at the end of the radiation treatment, nor was the data on chronic pain in 241 patients available after 9.8 years of follow-up $(\mathrm{OR}=0.74 \text {, range } 0.432-1.271)^{7,31}$

Six other clinical studies reported a comparison of the clinically adverse events in regard to the three groups of breast sizes. Four compared 2D-RT vs. IMRT $7,10,23,25,27$ in the supine position, one study compared 3D-CRT vs. IMRT in the prone position ${ }^{28}$, and one study compared conventional (CF) vs. HF

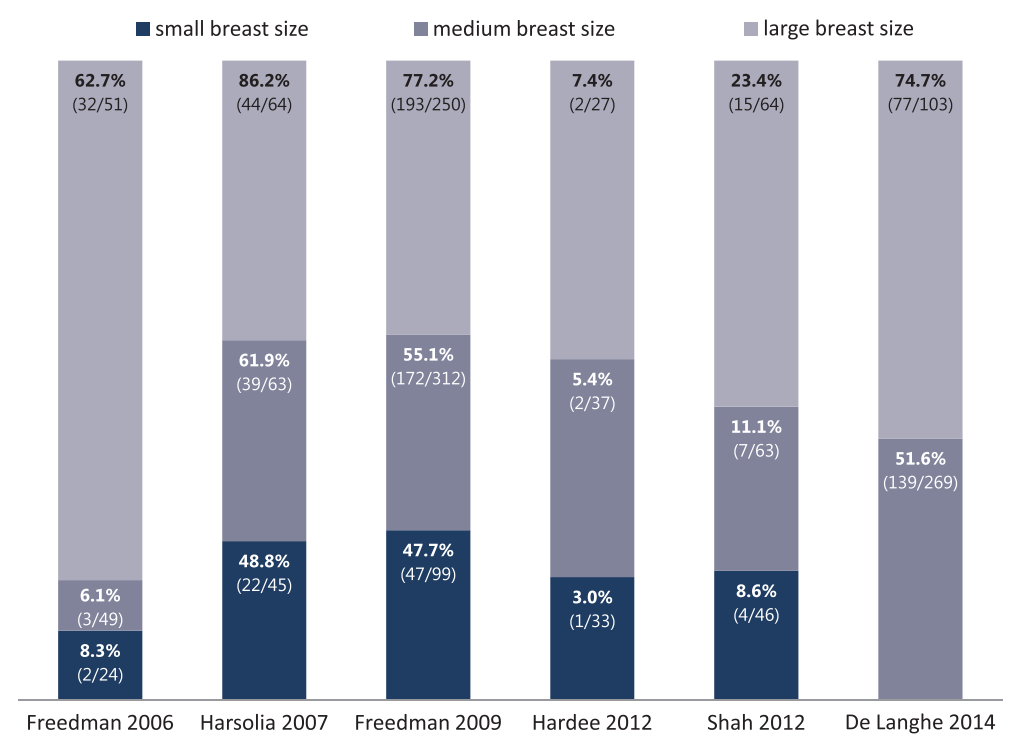

FIGURE 1. Percentage of patients experiencing $\geq G 2$ acute breast toxicity, categorised in groups of small, medium, or large-sized breasts as reported in selected studies. The numbers displayed in parentheses are the absolute numbers of patients experiencing toxicity and absolute numbers of patients in a group. De Langhe et al. grouped small and medium-sized breasts in one category.

in the prone or supine position (Table 1). ${ }^{32}$ The percentages of patients experiencing $\geq \mathrm{G} 2$ acute breast toxicity categorised in groups of small, medium, or large-sized are presented separately in Figure 1.

Harsolia et al. found a correlation between $\geq \mathrm{G} 2$ dermatitis, the development of chronic hyperpigmentation, and breast oedema with a larger than average breast size. ${ }^{25}$ Interestingly, no $\geq$ G3 toxicity was reported in smaller breast volumes in either treatment modality (2D-RT vs. IMRT). In comparison with 2D-RT, IMRT improved the rates of $\geq \mathrm{G} 2$ acute oedema ( $36 \%$ vs. $0 \%$, p < 0.001), $\geq$ G2 chronic oedema ( $30 \%$ vs. $3 \%, p=0.007)$, and $\geq \mathrm{G} 2$ hyperpigmentation $(41 \%$ vs. $3 \%, p=0.001)$ regardless of the breast volume. No statistically significant difference was observed in acute or chronic rates of $\geq \mathrm{G} 2$ acute dermatitis, pain, chronic hyperpigmentation, or breast induration. ${ }^{25}$

Increased rates of acute dermatitis, acute and chronic oedema, and chronic hyperpigmentation, irrespective of the treatment technique (prone $v s$. supine) or fractionation ( $\mathrm{CF}$ vs. HF), were noted in large-breasted patients (volume $>1.600 \mathrm{~cm}^{3}$ ) by Shah et al., when compared to patients with a smaller breast size. In large-breasted patients, IMRT was superior to the 2D-RT technique in reducing the rates of $\geq \mathrm{G} 2$ acute dermatitis ( $0 \%$ vs. $19 \%, \mathrm{p}=0.02)$ and oedema $(7 \%$ vs. $24 \%, \mathrm{p}=0.06) .{ }^{23}$ 
TABLE 1. Selected studies evaluating IMRT versus 2D-RT or 3D-CRT. Patients were further stratified by small, medium or large-sized breasts

\begin{tabular}{|c|c|c|c|c|c|c|c|c|c|c|}
\hline Study & $\begin{array}{l}\text { Number of } \\
\text { patients }\end{array}$ & Type of study & Technique & $\begin{array}{l}\text { Total dose and } \\
\text { Fractionation } \\
\mathrm{CF} / \mathrm{HF}\end{array}$ & $\begin{array}{l}\text { Breast size } \\
\text { (median breast } \\
\text { volume) } \mathrm{cm}^{3}\end{array}$ & $\begin{array}{l}\text { Scoring } \\
\text { system }\end{array}$ & $\begin{array}{l}\text { G1 or } \\
\text { G2 (\%) } \\
\text { (whole } \\
\text { group) }\end{array}$ & $\begin{array}{l}\text { G2 or } \\
\text { G3 (\%) } \\
\text { (whole } \\
\text { group) }\end{array}$ & $\begin{array}{l}\text { G3 or } \\
\text { G4 (\%) } \\
\text { (whole } \\
\text { group) }\end{array}$ & General comments \\
\hline $\begin{array}{l}\text { Harsolia, } \\
2007^{25}\end{array}$ & 172 & $\begin{array}{l}\text { Retrospective } \\
\text { study }\end{array}$ & $\begin{array}{l}\text { F-IMRT } \\
\text { 2D-RT }\end{array}$ & $\begin{array}{l}\text { CF } \\
\text { median dose } \\
45 \mathrm{~Gy}+16 \mathrm{~Gy} \\
\text { boost }\end{array}$ & $\begin{array}{l}1.326 \text { (IMRT) } \\
\text { 1.489 (2D-RT) } \\
\text { Breast volume } \\
\text { divided into groups: } \\
1.000 \mathrm{~cm}^{3}(\mathrm{smalll}) \text {, } \\
1.000-1.599 \mathrm{~cm}^{3} \\
\text { (medium), } 1.600 \mathrm{~cm}^{3} \\
\text { (large) }\end{array}$ & $\begin{array}{l}\mathrm{NCl} \\
\mathrm{CTC} \\
\text { v. } 2.0\end{array}$ & $\begin{array}{l}41 \text { (IMRT) } \\
85 \text { (2D-RT) }\end{array}$ & & $\begin{array}{l}1 \text { (IMRT) } \\
6 \text { (2D-RT) }\end{array}$ & $\begin{array}{l}\text { Lower rates of } \geq \mathrm{G} 2 \text { toxicity } \\
\text { with IMRT regardless of breast } \\
\text { size. } \\
\geq \mathrm{G} 2 \text { clinical toxicities } \\
\text { associated with larger } \\
\text { irradiated breast sizes, on } \\
\text { average }\left(<1.000 \mathrm{~cm}^{3} \text {; vs. }\right. \\
\left.>1.600 \mathrm{~cm}^{3}\right)\end{array}$ \\
\hline \multirow[t]{2}{*}{$\begin{array}{l}\text { Freedman } \\
200910\end{array}$} & \multirow[t]{2}{*}{804} & \multirow[t]{2}{*}{$\begin{array}{l}\text { Retrospective } \\
\text { study }\end{array}$} & \multirow[t]{2}{*}{$\begin{array}{l}\text { F-IMRT } \\
\text { 2D-RT }\end{array}$} & \multirow{2}{*}{$\begin{array}{l}46-50 \text { Gy in } \\
23-25 \text { fractions } \\
+ \text { boost } \\
10-18 \text { Gy }\end{array}$} & \multirow{2}{*}{$\begin{array}{l}\text { Bra size, (at least } \\
63 \% \text { with small and } \\
\text { medium sizes) } \\
\text { Small (32; 34A,B; } \\
36 \mathrm{~A}) \text {, Medium (34C; } \\
36 \mathrm{~B}, \mathrm{C} ; 38 \mathrm{~B}, \mathrm{~B}, \mathrm{C}) \text {; } \\
\text { Large (any D or } \\
\text { size 40+) }\end{array}$} & \multirow[t]{2}{*}{$\begin{array}{l}\text { CTCAE } \\
\text { v. } 3.0\end{array}$} & & \multirow[t]{2}{*}{$\begin{array}{l}52 \text { (IMRT) } \\
75 \text { (2D-RT) }\end{array}$} & & $\begin{array}{l}\text { More large-breasted patients } \\
\text { in IMRT group. }\end{array}$ \\
\hline & & & & & & & & & & $\begin{array}{l}\text { IMRT reduces the incidence of } \\
\geq \mathrm{G} 2 \text { dermatitis in women of all } \\
\text { breast sizes. }\end{array}$ \\
\hline $\begin{array}{l}\text { Shah } \\
2012^{23}\end{array}$ & 335 & $\begin{array}{l}\text { Prospective } \\
\text { study }\end{array}$ & $\begin{array}{l}\text { IMRT } \\
\text { 2D-RT } \\
\text { IMRT: }\end{array}$ & $\begin{array}{l}\text { Median } \\
\text { dose } 45 \mathrm{~Gy}+ \\
\text { boost } 16 \mathrm{~Gy}\end{array}$ & $\begin{array}{l}1.378 \text { for the whole } \\
\text { group }\end{array}$ & $\begin{array}{l}\text { CTCAE } \\
\text { v. } 3.0\end{array}$ & & $\begin{array}{l}1 \text { (CF- } \\
\text { IMRT) } \\
23 \text { (HF- } \\
\text { IMRT) } \\
12 \text { (2D-RT) }\end{array}$ & & $\begin{array}{l}\text { IMRT is associated with } \\
\text { reduced toxicities compared } \\
\text { with 2D radiotherapy. }\end{array}$ \\
\hline $\begin{array}{l}\text { De } \\
\text { Langhe } \\
2014^{32}\end{array}$ & 377 & $\begin{array}{l}\text { Prospective } \\
\text { study }\end{array}$ & $\begin{array}{l}\text { Prone or supine } \\
\text { position with } \\
\text { INV-IMRT or } \\
\text { prone with } \\
\text { F-IMRT or prone } \\
\text { position with } \\
\text { DIBH ( } n=22 \text { ) or } \\
\text { supine F-IMRT } \\
\pm \text { DIBH }\end{array}$ & 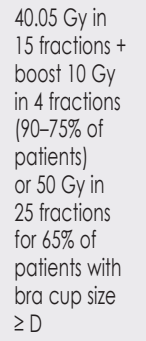 & $\begin{array}{l}\text { Breast size was } \\
\text { classified } A, B, C \\
\text { and } \geq D \text { cup }\end{array}$ & $\begin{array}{l}\text { CTCAE } \\
\text { v. } 3.0\end{array}$ & & $\begin{array}{l}57.3 \\
(\geq \mathrm{G} 2)\end{array}$ & & $\begin{array}{l}\text { CF, supine IMRT, concomitant } \\
\text { hormone treatment, high } \\
\text { BMI, large breast, smoking } \\
\text { during treatment, and genetic } \\
\text { variation (in MLHI rs } 1800734 \text { ): } \\
\text { all were associated with } \geq \mathrm{G} 2 \\
\text { toxicity. }\end{array}$ \\
\hline
\end{tabular}

2D-RT = standard 2D wedged plan; CTCAE v. $3.0=$ common terminology criteria for adverse events for acute radiation dermatitis, version 3.0; CF = conventional fractionation $\mathrm{HF}=$ hypofractionation; DIBH = deep inspiration breath hold; F-IMRT = forward planned intensity modulated radiotherapy; $\mathrm{H}-\mathrm{IMRT}=\mathrm{hybrid}$ intensity modulated radiotherapy; NC CTC v. 2.0 = National Cancer Institute common toxicity criteria; version 2.0; RTOG = Radiation Therapy Oncology Group criteria 
Acute skin toxicity, especially moist desquamation, is associated with late complications of radiotherapy, namely telangiectasia and late subcutaneous fibrosis, as shown in a ten-year update of a Canadian breast IMRT trial and other studies. ${ }^{31,33}$ Five-year results of simple IMRT (F-IMRT) support the use of $\mathrm{BC}$ adjuvant radiotherapy technique that improves homogeneity: the benefit of IMRT was confirmed in a multivariate analysis for both overall cosmesis $(p=0.038)$ and skin telangiectasia $(p=0.031)$, although there was no difference in breast shrinkage, breast oedema, tumour bed induration, or pigmentation..$^{24}$

\section{Hypofractionation}

Moderate HF schedule is an established adjuvant treatment in lymph node-negative BC after breast conserving surgery with no differences in diseaserelated outcomes and with a favourable toxicity profile. ${ }^{34-37}$ Moreover, shorter treatment schedules are a cost-effective approach for both the patient and healthcare providers. ${ }^{38}$ The advantages of a hypofractionated schedule over conventional fractionation, e.g. convenience, a less acute pain, fatigue, and dermatitis, were recently confirmed with prospectively collected physician-assessed data and patient-reported outcome measures in a large comparative analysis by Jagsi et al. ${ }^{37}$ In this multicentre cohort, the mean breast volume, BMI, and separation distance were slightly smaller in the hypofractionated group: 1270 vs. $980 \mathrm{~cm}^{3}, 23$ vs. $21.9 \mathrm{~cm}$, and 30.8 vs. 28.7, respectively. ${ }^{37}$

A higher daily fraction size (> 1.8-2.0 Gy) and hot spots (> V105\%) may contribute to so-called 'triple trouble' or an unequal distribution of the biological effective dose (BED), although the risk is probably insignificant. ${ }^{39,40}$ To avoid any of the possible complications (greater fibrosis or late normal tissue effects) with $\mathrm{HF}$, it is generally recommended to limit the volume of hot spots and not to exceed $107 \%$ of the prescribed dose. ${ }^{40}$ Some authors suggest that patients with a large breast size that precludes achieving the maximum dose of $>107 \%$ should be offered a dose/fractionation that is biologically less intense, for example $45 \mathrm{~Gy}$ in 25 daily fractions at $1.8 \mathrm{~Gy}$ daily with an addition of a boost dose. ${ }^{41}$

Similarly as with the CF schedule, high BMI, an increasing PTV volume with a cut off value as small as $500 \mathrm{~cm}^{332,35,42}$, and excessive radiation dose in the target volume (i.e. V107-110\%) contribute to increased acute skin toxicity. ${ }^{17,42}$ When CF was compared to HF, the CF schedule was a predictive factor for increased $\geq \mathrm{G} 2$ toxicity..$^{17,32,35}$ One study reported no differences in acute skin toxicity when HF was compared to CF in similar groups of largebreasted women (volume $>1.500 \mathrm{~cm}^{3}$ ), $\mathrm{BMI}>30$, or breast separation $>25 \mathrm{~cm}$. Breast volume was the only patient factor significantly associated with moist desquamation in a multivariable analysis $(p=0.01)$. A very large breast volume $\left(>2.500 \mathrm{~cm}^{3}\right)$ had a higher rate of focal moist desquamation $(40.7 \%)$ compared to breast volume $<2.500 \mathrm{~cm}^{3}$ $(11.1 \%)(p=0.002) .{ }^{11}$ In a randomised clinical trial by Shaitelman et al., where three-quarters of patients were overweight or obese and half of the patients had a Dmax of $107 \%$ or higher, the authors have confirmed the administration of the HF schedule in regard to acute toxic effects to be safe. ${ }^{36}$

\section{Lung and heart toxicity}

The dose-volume predictors for acute and late radiation-induced toxicities are established for the lung and heart as a whole structure. ${ }^{43-45}$ Recent studies have evaluated the dose to the whole heart and the proportional increase in cardiac events after $B C$ radiotherapy. An estimated linear increase of $7.4 \%$ and $4.1 \%$ was found per every Gy mean dose to the whole heart for major coronary events and cardiac mortality, respectively. ${ }^{9,45}$ A systematic literature review on modern radiation doses to heart and lung in BC radiotherapy showed an estimated absolute 30-year risk for cardiac mortality of $1 \%$ for smokers and $0.3 \%$ for non-smokers. ${ }^{9}$ Patient-related factors (age and smoking), systemic therapy, the fractionation schedule (total dose and daily fraction), and dose-volume parameters of radiation treatment plan such as mean dose to the whole lung and V20, all constitute risk factors for pneumonitis and lung fibrosis. . $^{15,43}$

In a recent retrospective clinical study of 4688 WBRT-treated BC patients, it was reported that larger breast separation $(>22 \mathrm{~cm})$ was one of the factors significantly increasing the mean heart dose (MHD) for CF by $1.5 \%$ per $1 \mathrm{~cm}$ and in HF by $1.7 \%$ per every $1 \mathrm{~cm}$ increase, respectively. ${ }^{46}$ It has been demonstrated that the dose to the heart can be significantly reduced in both CF and HF by means of breathing adaptation and prone positioning. ${ }^{13,46}$

Hannan et al. found that increasing breast size results in increased mean and maximum point heart doses. ${ }^{13}$ PTV, BMI, or age were generally unrelated to ipsilateral lung dose. The lung dose decreased markedly in the prone compared to supine position for the whole group of patients. Largebreasted prone-treated patients received a higher ipsilateral lung D5 (greatest dose delivered to 
$5 \mathrm{~cm}^{3}$ ) compared to small-breasted prone-treated patients (PTV $<1000 \mathrm{~cm}^{3}$ ), but without significant differences in V5 or V20. ${ }^{13}$ Breast shape (i.e. pendulous breasts) can contribute to a higher maximum heart dose as well. ${ }^{47}$ One small dosimetric study in free-breathing supine-position radiation therapy did not find a correlation of increasing breast separation with higher heart doses, but instead found a correlation with an increased dose to the ipsilateral lung (parameters V5 Gy, V10 Gy and V20 Gy), with the greatest increase noted in breast separation between 25 and $27 \mathrm{~cm} .{ }^{48}$ By contrast, Hardee et al. found an opposite association between breast size and lung dosimetric parameters in the prone position (in-field lung volume, V5, and Dmax). All parameters decreased as breast size increased. ${ }^{28}$

\section{Secondary malignancy risk}

In $\mathrm{BC}$ radiotherapy, differences in body habitus may influence doses to organs at risk, but it is not known if small differences in radiation exposure at the time of the first radiation course significantly influence the risk of a secondary non-breast cancer. Compared to the general population, BC patients have an increased risk of secondary non-breast cancers, five or more years after BC diagnosis with and without radiation therapy (RR 1.12; $95 \%$ confidence interval [CI] 1.06-1.19). ${ }^{49}$ But probably less than $3.5 \%$ of secondary malignancies in BC survivors are attributable to radiation therapy.$^{50}$ The total dose of radiation, premenopausal age $(<40-45$ years) and the irradiated volume of normal tissue all increase the risk for secondary lung, oesophageal, or thyroid cancer, and secondary sarcomas. ${ }^{49,51}$ The risk of lung cancer increases with the mean dose to the whole lung. ${ }^{52} \mathrm{~A}$ systematic review of modern radiation doses to the lung in $\mathrm{BC}$ radiotherapy showed an estimated absolute 30-year risk for lung cancer of $4 \%$ for long-term continuing smokers and $0.3 \%$ for non-smokers. ${ }^{9}$

The radiation dose to the lung increases with lymph node irradiation and the use of IMRT techniques, and decreases with breathing adaptations and prone/lateral decubitus positioning. ${ }^{52}$ Younger women $(<40$ years of age) with an absorbed radiation dose $>1.0 \mathrm{~Gy}$ to the contralateral breast have an elevated long-term risk of developing a second primary contralateral BC. ${ }^{52}$

A study by Bhatnagar et al. suggests that the size of the primary irradiated breast significantly affects the scatter dose to the contralateral breast but not the ipsilateral lung or heart when using IMRT for breast irradiation. The mean volume of the primary irradiated breast in the study was $1167.9 \mathrm{~cm}^{3} .{ }^{53}$ However, Jin et al. found that in the population of women with smaller breasts ( 360.8 $\left.\pm 149.1 \mathrm{~cm}^{3}\right)$, the size of the treated breast does not significantly increase the dose to the contra-lateral breast with 2D-RT, 3D-CRT with 3-5 subfields, or tangential IMRT techniques. ${ }^{54}$

\section{Strategies to modify acute toxicity and dose to organs at risk}

Different strategies in BC radiotherapy exist to lower the dose to organs at risk. Approaches could be further divided according to patient or breast positioning modification, breathing adaptation, and treatment volume reduction.

\section{Patient positioning modification}

The prone positioning setup demonstrated to be an excellent strategy to spare the ipsilateral lung in $100 \%$ and heart dose in $85-87 \%$ of the patients, independently of their BMI or breast size $\mathrm{e}^{12,55-58}$, but a particular benefit was observed in large-breasted women $\left(\mathrm{CTV}>1000 \mathrm{~cm}^{3}\right)$. $^{12,13,57}$ Similar findings were confirmed in a study by Formenti et al. but, in this study, the prone treatment position did not necessarily spare the heart in patients with breast volumes smaller than $750 \mathrm{~cm}^{3} .57$ On the other hand, one study reported having achieved similar heart doses for prone and supine 3D-CRT WBRT in women with large breast volumes (the average treated volume was $1804 \mathrm{~cm}^{3}$ in right-sided breasts and $1500 \mathrm{~cm}^{3}$ in left-sided breasts). They also noted a significantly higher incidental dose to the LADCA in the prone position with left-sided BC.59

3D-CRT lateral isocentric decubitus position was recently described as a treatment planning solution. Long-term toxicity results were published by the Institut Curie group. ${ }^{14,60}$ Women with a median BMI of 26.3 were treated with different types of fractionation. Acute dermatitis of any grade was present in $93 \%$ of the patients and G3 dermatitis in only $2.8 \%$. In a 1-year follow-up, $94.1 \%$ of cases had no skin reaction, making this technique feasible with excellent toxicity rates, but the results need to be confirmed with a longer follow-up. In a multivariate analysis, the cup size and the fractionation had a significant influence on acute dermatitis. ${ }^{14}$

\section{Breathing adaptation}

The deep inspiration breath-hold (DIBH) technique helps to minimise the "trade-off" between 
the target and OAR, a compromise often required, and is less resource-intensive than the IMRT technique. It reduces the low-dose irradiation to the heart, left anterior descending coronary artery (LADCA), and lung, ultimately benefiting women of all breast sizes. ${ }^{61}$ DIBH can be accurately clinically implemented with an acceptable reproducibility and stability in both supine and prone position. ${ }^{61,62}$ In a group of women with a volume of the treated breast $>750 \mathrm{~cm}^{3}$, supine voluntary DIBH enabled a cardiac sparing and reproducibility superior to that of free-breathing prone position. ${ }^{63}$

\section{Partial breast irradiation}

Another strategy to lower the absorbed radiation dose to the heart is partial breast irradiation. Patients may benefit in terms of lower mean whole heart doses with moderate HF using 3D-CRT and the accelerated partial breast irradiation technique (APBI) with an external beam or interstitial brahcytherapy. ${ }^{64-67}$ Meszaros et al. demonstrated the reproducibility of image-guidance intensity modulated APBI and feasibility in terms of acute toxicity and the cosmetic outcome with a median follow up of 3.2 years. In a study, $55 \%$ of the patients had cup size $C$ and $21 \%$ cup size $\geq D$ D. ${ }^{67}$ Investigators emphasised the necessity of image guidance prior to each radiation fraction to reduce the CTV to PTV margins. ${ }^{67}$

\section{Breast tissue modification}

A thermoplastic bra which helps to raise the lateral breast border is also an option to lower the dose to thoracic organs in $\mathrm{BC}$ radiotherapy. Piroth et al. demonstrated an excellent reduction in radiation exposure to the heart (mean dose reduction by $\approx$ $23 \%$ ) and ipsilateral lung (mean dose reduction by $\approx 30 \%$ and V20 by $39.5 \%$ ) without additional skin toxicity in women of all breast sizes (clinical target volume ranging from 283.1 to $\left.1581.6 \mathrm{~cm}^{3}\right){ }^{68}$

\section{Treatment planning studies}

Many different treatment planning options are available in the modern treatment era: 3D-CRT with or without wedged filters, forward-planned IMRT (F-IMRT), inverse-planned IMRT (INVIMRT), Helical Tomotherapy (HT), VMAT, and hybrid techniques (H-IMRT). The recommended first choice for WBRT varies across numerous treatment planning studies comparing different modalities (i.e. 3D-CRT vs. IMRT vs. VMAT) and usually de- pends on the available equipment, technical innovations, irradiated volume, treatment planning system with dose calculation algorithm, and skills of the planner.

There are numerous publications comparing the dosimetric parameters of radiotherapy plans, mostly for patients with left-sided early BC. Some of them have been summarised in a review of treatment planning options by Balaji et al. where most authors favoured hybrid planning techniques (3D CRT + IMRT/VMAT) while weighing the target coverage $v s$. dose to the organs at risk. ${ }^{69}$ While INV-IMRT is not routinely recommended after breast-only radiation, the use of advanced techniques is increasing in challenging anatomy cases (up to $9.4 \%$ of all BC patients treated with radiotherapy). ${ }^{70}$ The majority of techniques can be combined with DIBH and/or the prone position. The role of the VMAT technique in clinical practice is still not known precisely and the technique itself is not routinely recommended. The dosimetric data, although promising, need to be validated from a clinical point of view. ${ }^{71}$ The VMAT technique is sometimes the first choice in complex anatomy cases (including large breasts, bilateral BC adjuvant radiotherapy, pectus excavatum, etc.). ${ }^{71} \mathrm{HT}$ (TomoDirect) can be delivered in a 3D-CRT or IMRT modality in whole-breast adjuvant BC radiotherapy. Both HT modalities have a good PTV coverage and dose homogeneity, but some caution is needed as the dose to ipsilateral lung and heart can be significantly high with the 3D-CRT modality in specific patient anatomic situations. Authors have proposed that simple anatomic measures like maximal heart distance can be helpful in selecting the appropriate treatment strategy. ${ }^{72}$

For the purpose of this review, we have evaluated the treatment planning studies which included at least coronary arteries or cardiac chambers as organs at risk. Overall, we have found eight treatment planning studies comparing radiotherapy plans in free-breathing CTs. ${ }^{54,73-79}$ The studies indicate an improved dose homogeneity with the IMRT $^{54,73,75,78,79}$ or VMAT $^{73,74}$ techniques regardless of the PTV volume, but the number of CT study sets compared was relatively low (10-20). The sizes of the target volumes reported by investigators comparing treatment planning approaches were dissimilar, ranging from $296 \mathrm{~cm}^{3}$ (mean value) to $1160 \mathrm{~cm}^{3}$ (median value). ${ }^{74,79}$ A study by Tan et al. found additional heart subvolumes (left ventricle or LV and anterior myocardial territory or AMT) to be helpful in the IMRT plan optimization process, although there have been no reports available so 
far for the dose-volume constraints in these two OARs. ${ }^{75}$

Besides the heart as a whole structure, authors typically delineated $\mathrm{LADCA}^{73,74,76-78}$, $\mathrm{LV}^{75,76,78,79}$, right ventricle $(\mathrm{RV})^{76,78}$, left atrium $(\mathrm{LA})^{76,78}$, right atrium $(\mathrm{RA})^{76,78}$, great vessels ${ }^{78}$, and AMT. ${ }^{54,74,75}$ The delineation of heart substructures was not uniformly defined or was rarely guided by written instructions, making it difficult to compare the presented studies. ${ }^{54,74,75}$

\section{Discussion}

Growing clinical data on BC adjuvant radiotherapy suggest that a smaller PTV and/or the use of the IMRT technique may be associated with a decreased rates of acute breast toxicity. Most studies evaluated women with small or medium-sized breasts, so maybe all of the results are not directly applicable in large-breasted woman. The clinical studies which reported a comparison of the clinical adverse events in regard to the three categories of breast sizes mostly used the CTCAE v.3.0 scoring system. 7,10,23,25,27,28 The rates of $\geq \mathrm{G} 2$ toxicity for the whole group of patients from selected studies used in Figure 1 ranged from $5.1 \%$ to $70 \%$. The percentage of patients with $\geq$ G2 toxicity was the highest in the subcategory of large-breasted patients in all the studies, ranging from $7.4 \%$ to $86.2 \% .^{10,23,27,32}$ The differences in adverse event reporting could at least partly be attributed to different scoring systems, i.e. the subjective scoring by investigators and different planning techniques.

Moderately hypofractionated schedules proved superiority over CF and conformal radiation therapy (3D-CRT or F-IMRT) over 2D-RT in terms of acute and late adverse effects in early BC WBRT.7,12,22,24,26,34,37 Clinical reports are confirming the long-term safety and feasibility of moderately hypofractionated schedules also in women with large breasts. ${ }^{11,17,32,36,38,42,80,81}$ Most of the investigators attributed higher toxicity rates in $\mathrm{BC}$ radiotherapy to dose inhomogeneity and a higher percentage of hot spots, irrespective of breast volume. ${ }^{7,12,17,31}$ V105-107 \% of the prescribed dose (PD) was significantly related to increased desquamation, dermatitis, oedema, and pain ${ }^{12}$; and V105 \% PD ${ }^{82,83}$ or V110 \% PD ${ }^{83}$ to long-term breast pain. Significant reductions in hot spots can be achieved with 3D-CRT or F-IMRT treatment plans, also in patients with large/pendulous breasts (PTV $\left.>1000 \mathrm{~cm}^{3}\right) \cdot{ }^{20,26,28,84}$ An improvement in dose homogeneity was achieved with IMRT, and correlated with less acute toxicity rates in a study by Mulliez et al. ${ }^{85}$

However, some of the studies show that large breast volume seems to be a risk factor for acute or late adverse events independently of dose inhomogeneity and regardless of the conformal radiotherapy technique (3D-CRT vs. IMRT) or fractionation schedule. ${ }^{11,24,86}$ A retrospective analysis of selected patients from UK FAST hypofractionation (3D-CRT) trial found that breast size and dosimetric parameters are significantly associated with late effects in a univariate analysis where breast size was the only remaining independent significant risk factor for change in breast appearance when included in a multiple regression model together with other prognostic factors. ${ }^{86}$ Investigators failed to correlate the breast composition (breast tissue distribution and scar tissue presence) with late adverse effects, with the exception of seroma. ${ }^{87}$ Combining all data, there is no reason to withhold the hypofractionation schedule in large-breasted women.

The data published support the hypothesis that every Gy of increase in the whole lung mean dose increases the risk for second lung cancer. ${ }^{9}$ In the long run, as far as the sub-population of continuing smokers is concerned, the second lung cancer risk is even greater and the benefits of adjuvant radiotherapy in early BC may be reduced to the point where long-term risks outweigh the benefits of adjuvant radiotherapy. ${ }^{9}$ At the same time smokers, portend lifelong cardiac mortality risks and smoking during BC radiotherapy significantly increase the risk of acute $\geq$ G2 dermatitis. ${ }^{32,52}$ Smoking cessation counselling may be provided to modify acute and late toxicity risks. Breathing-adapted radiotherapy in the prone or supine position in women with all breast sizes, and prone or lateral setup in medium or large-breasted patients (approximately $\geq 1000 \mathrm{~cm}^{3}$ ) have been shown to decrease the whole lung and heart dose parameters. ${ }^{12,13,52,57,88}$

In terms of the heart as an organ at risk, ideally, all treatment planning comparisons of WBRT in patients with left-sided BC should be done in DIBH. Treatment planning or retrospective dose evaluation studies often only include the heart as a whole structure, without separately delineated heart subvolumes, although the dose distribution in the heart itself in BC adjuvant radiotherapy is usually not homogeneous. ${ }^{89}$ In some patients, the dose to the LADCA can be significantly higher in the prone (without breath-hold) compared to the supine setup, which could also be attributed to the differences in contouring and treatment tech- 
niques. ${ }^{59}$ The routine use of delineation guidelines for thoracic organs at risk and dose reporting with clinical correlation could help us further understand normal tissue complication probability models, especially in the least known dose-response relationships, i.e. for coronary arteries and cardiac chambers. Using individual 3D-CRT planning data, one study independently validated the mean heart dose-based normal tissue complication probability (NTCP) model (published by Darby et al. in $2013^{45}$ ) for acute coronary events within 9 years after adjuvant radiotherapy. Investigators found an increase of $16.5 \%$ in the cumulative incidence of acute coronary events per every Gy increase of the mean heart dose. One step further was made in understanding the radiation tolerance for particular cardiac segments, as there are no current models for dose-response relationships. The study found a significant prognostic importance of the left ventricle V5 Gy dose relationship with an acute coronary event. ${ }^{44,90}$

Treatment planning studies usually compare a limited number of CT study sets and it is not known if small improvement in dosimetric metrics would translate into clinically meaningful lower rates of adverse events for the larger population. For example, one treatment planning study in the modern treatment era reported very little difference in dosimetric parameters between patients of different breast size regardless of the modality (static HT, IMRT, and 3D-CRT). ${ }^{21}$ Expected absolute differences in the rates of clinical adverse events (3D-CRT vs. other highly conformal techniques) are likely negligible. HT, INV-IMRT, and VMAT may all increase the mean and maximum dose to contralateral breast, and mean dose to the heart and ipsilateral lung compared to F-IMRT or 3D CRT, although doses to organs at risk may also depend on the patient's anatomy or positioning. ${ }^{52,73,75,91}$

In order to de-escalate radiotherapy, selected patients will be treated routinely with the moderate HF or accelerated partial breast irradiation techniques (treating only the tumour bed with a safety margin) in the near future, as emerging data confirm a similar 5-year cumulative incidence of loco-regional and distant relapse compared to WBRT. ${ }^{38,92,93}$ In a 5-year assessment, patients treated with partial radiotherapy approaches self-reported less moderate or marked skin $(p=0.051)$ or overall breast appearance change $(\mathrm{p}<0.0001)$ compared to the WBRT group. ${ }^{88}$ APBI using interstitial brachytherapy was able to significantly reduce acute G3 skin toxicity (7\% in WBRT group vs. $0.2 \%$; p < 0.0001). ${ }^{94}$ Simple F-IMRT techniques using short- ened tangential fields and interstitial brachytherapy APBI were able to minimise the dose to the heart and lung. ${ }^{66,92}$ A higher APBI-PTV/breast volume ratio most probably contributes to adverse acute and poor final cosmetic results. ${ }^{67}$ Further clinical trials with longer follow-ups are needed in partial breast radiotherapy, especially in large-breasted woman, to confirm the clinical relevance.

\section{Conclusions}

One of the important individual factors affecting the final cosmetic outcome of radiation therapy treatment is the size of the treated PTV. It seems that beside the target volume, inhomogeneity, and a higher percentage of the excessive radiation dose, bigger breast size itself is an independent risk factor for acute adverse effects regardless of the fractionation regimen or dose inhomogeneity, although the lower the excessive radiation dose, the lower the risk of $\geq \mathrm{G} 2$ toxicity. While weighing the risk of BC relapse vs. acute or late treatment toxicity, an appropriate postoperative radiotherapy technique (3D-CRT vs. modulated approaches), patient setup (prone vs. supine with or without a breath hold), and volume irradiated (i.e. candidates for partial breast irradiation) should be optimally selected and tailored to the patient's anatomy (including BMI, breast separation, or cup size), age, and tumour characteristics. A personalised approach is therefore needed in every single patient, with the patient's social, economic, or psychological issues to be taken into account.

\section{References}

1. Borras JM, Lievens Y, Barton M, Corral J, Ferlay J, Bray F, et al. How many new cancer patients in Europe will require radiotherapy by 2025 ? An ESTRO-HERO analysis. Radiother Oncol 2016; 119: 5-11. doi: 10.1016/j. radonc.2016.02.016

2. Fisher B, Anderson S, Bryant J, Margolese RG, Deutsch M, Fisher ER, et al. Twenty-year follow-up of a randomized trial comparing total mastectomy, lumpectomy, and lumpectomy plus irradiation for the treatment of invasive breast cancer. N Engl J Med 2002; 347: 1233-41. doi: 10.1056/ NEJMoa022152

3. Veronesi U, Cascinelli N, Mariani L, Greco M, Saccozzi R, Luini A, et al. Twenty-year follow-up of a randomized study comparing breast-conserving surgery with radical mastectomy for early breast cancer. N Eng/J Med 2002; 347: 1227-32. doi: 10.1056/NEJMoa020989

4. Gentilini OD, Cardoso M-J, Poortmans P. Less is more. Breast conservation might be even better than mastectomy in early breast cancer patients. Breast 2017; 35: 32-3. doi: 10.1016/j.breast.2017.06.004

5. Arndt V, Stegmaier C, Ziegler H, Brenner H. Quality of life over 5 years in women with breast cancer after breast-conserving therapy versus mastectomy: a population-based study. J Cancer Res Clin Oncol 2008; 134: 1311-8. doi: 10.1007/s00432-008-0418-y 
6. Berry S. Advances in breast bancer radiotherapy and the impact on quality of life. J Cancer Biol Res 2014; 2: 1041

7. Pignol J-P, Olivotto I, Rakovitch E, Gardner S, Sixel K, Beckham W, et al. A multicenter randomized trial of breast intensity-modulated radiation therapy to reduce acute radiation dermatitis. J Clin Oncol 2008; 26: 2085-92. doi: $10.1200 / J C O .2007 .15 .2488$

8. Pignol J-P, Vu TTT, Mitera G, Bosnic S, Verkooijen HM, Truong P. Prospective evaluation of severe skin toxicity and pain during postmastectomy radiation therapy. Int J Radiat Oncol 2015; 91: 157-64. doi: 10.1016/j. ijrobp.2014.09.022

9. Taylor C, Correa C, Duane FK, Aznar MC, Anderson SJ, Bergh J, et al. Estimating the risks of breast cancer radiotherapy: evidence from modern radiation doses to the lungs and heart and from previous randomized trials. J Clin Oncol 2017; 35: 1641-9. doi: 10.1200/JCO.2016.72.0722

10. Freedman GM, Li T, Nicolaou N, Chen Y, Ma CC-M, Anderson PR. Breast intensity-modulated radiation therapy reduces time spent with acute dermatitis for women of all breast sizes during radiation. Int J Radiat Oncol 2009; 74: 689-94. doi: 10.1016/j.jijobp.2008.08.071

11. Corbin KS, Dorn PL, Jain SK, Al-Hallaq HA, Hasan Y, Chmura SJ. Hypofractionated radiotherapy does not increase acute toxicity in largebreasted women: results from a prospectively collected series. Am J Clin Oncol 2014; 37: 322-6. doi: 10.1097/COC.0b013e31827b45b7

12. Mulliez T, Veldeman L, van Greveling A, Speleers B, Sadeghi S, Berwouts $D$, et al. Hypofractionated whole breast irradiation for patients with large breasts: a randomized trial comparing prone and supine positions. Radiother Oncol 2013; 108: 203-8. doi: 10.1016/j.radonc.2013.08.040

13. Hannan R, Thompson RF, Chen Y, Bernstein K, Kabarriti R, Skinner W, et al. Hypofractionated Whole-Breast Radiation Therapy: Does Breast Size Matter? Int J Radiat Oncol 2012; 84: 894-901. doi: 10.1016/j. ijrobp.2012.01.093

14. Bronsart E, Dureau S, Xu HP, Bazire L, Chilles A, Costa E, et al. Whole breast radiotherapy in the lateral isocentric lateral decubitus position: Longterm efficacy and toxicity results. Radiother Oncol 2017; 124: 214-9. doi: 10.1016/j.radonc.2017.07.001

15. Meattini I, Guenzi M, Fozza A, Vidali C, Rovea P, Meacci F, et al. Overview on cardiac, pulmonary and cutaneous toxicity in patients treated with adjuvant radiotherapy for breast cancer. Breast Cancer 2016; 24: 52-62. doi: 10.1007/ s12282-016-0694-3

16. Méry B, Vallard A, Trone J-C, Pacaut C, Guy J-B, Espenel S, et al. Correlation between anthropometric parameters and acute skin toxicity in breast cancer radiotherapy patients: a pilot assessment study. Br J Radiol 2015; 88: 20150414. doi: 10.1259/bjr.20150414

17. Tortorelli G, Di Murro L, Barbarino R, Cicchetti S, di Cristino D, Falco MD, et al. Standard or hypofractionated radiotherapy in the postoperative treatment of breast cancer: a retrospective analysis of acute skin toxicity and dose inhomogeneities. BMC Cancer 2013; 13: 230. doi: 10.1186/14712407-13-230

18. Dundas KL, Atyeo J, Cox J. What is a large breast? Measuring and categoriz ing breast size for tangential breast radiation therapy. Australas Radiol 2007 51: 589-93. doi: 10.1111/j.1440-1673.2007.01898.x

19. Back M, Guerrieri M, Wratten C, Steigler A. Impact of radiation therapy on acute toxicity in breast conservation therapy for early breast cancer. Clin Oncol (R Coll Radiol) 2004; 16: 12-6. doi: 10.1016/j.clon.2003.08.005

20. Vicini FA, Sharpe M, Kestin L, Martinez A, Mitchell CK, Wallace MF, et al. Optimizing breast cancer treatment efficacy with intensity-modulated radiotherapy. Int J Radiat Oncol Biol Phys 2002; 54: 1336-44. doi: 10.1016/ S0360-3016(02)03746-X

21. Michalski A, Atyeo J, Cox J, Rinks M, Morgia M, Lamoury G A dosimetric comparison of 3D-CRT, IMRT, and static tomotherapy with an SIB for large and small breast volumes. Med Dosim 2014; 39: 163-8. doi: 10.1016/j. meddos.2013.12.003

22. Donovan E, Bleakley N, Denholm E, Evans P, Gothard L, Hanson J, et al. Randomised trial of standard 2D radiotherapy (RT) versus intensity modulated radiotherapy (IMRT) in patients prescribed breast radiotherapy. Radiother Oncol 2007; 82: 254-64 doi: 10.1016/j.radonc.2006.12.008

23. Shah C, Wobb J, Grills I, Wallace M, Mitchell C, Vicini FA. Use of intensity modulated radiation therapy to reduce acute and chronic toxicities of breast cancer patients treated with traditional and accelerated whole breast irradiation. Pract Radiat Oncol 2012; 2: e45-51. doi: 10.1016/j.prro.2012.01.008
24. Mukesh MB, Barnett GC, Wilkinson JS, Moody AM, Wilson C, Dorling L, et al. Randomized controlled trial of intensity-modulated radiotherapy for early breast cancer: 5-year results confirm superior overall cosmesis. J Clin Oncol 2013; 31: 4488-95. doi: 10.1200/JCO.2013.49.7842

25. Harsolia A, Kestin L, Grills I, Wallace M, Jolly S, Jones C, et al. Intensitymodulated radiotherapy results in significant decrease in clinical toxicities compared with conventional wedge-based breast radiotherapy. Int J Radiat Oncol Biol Phys 2007; 68: 1375-80. doi: 10.1016/j.jijrobp.2007.02.044

26. Barnett GC, Wilkinson J, Moody AM, Wilson CB, Sharma R, Klager S, et al. A randomised controlled trial of forward-planned radiotherapy (IMRT) for early breast cancer: baseline characteristics and dosimetry results. Radiother Oncol 2009; 92: 34-41. doi: 10.1016/j.radonc.2009.03.003

27. Freedman GM, Anderson PR, Li J, Eisenberg DF, Hanlon AL, Wang L, et al. Intensity Modulated Radiation Therapy (IMRT) Decreases Acute Skin Toxicity for Women Receiving Radiation for Breast Cancer. Am J Clin Oncol 2006; 29: 66-70. doi: 10.1097/01.coc.0000197661.09628.03

28. Hardee ME, Raza S, Becker SJ, Jozsef G, Lymberis SC, Hochman T, et al. Prone hypofractionated whole-breast radiotherapy without a boost to the tumor bed: comparable toxicity of IMRT versus a 3D conformal technique. Int $J$ Radiat Oncol 2012; 82: e415-23. doi: 10.1016/j.jirobp.2011.06.1950

29. McDonald MW, Godette KD, Butker EK, Davis LW, Johnstone PAS. Long-term outcomes of IMRT for breast cancer: a single-institution cohort analysis. Int $J$ Radiat Oncol Biol Phys 2008; 72: 1031-40. doi: 10.1016/j.ijrobp.2008.02.053

30. Jensen KE, Soril LJ, Stelfox HT, Clement FM, Lin Y, Marshall DA. Side effects associated with the use of intensity-modulated radiation therapy in breast cancer patients undergoing adjuvant radiation therapy: a systematic review and meta-analysis. J Med Imaging Radiat Sci 2017; 48: 402-13. doi: 10.1016/j.jmir.2017.09.002

31. Pignol J-P, Truong P, Rakovitch E, Sattler MG, Whelan TJ, Olivotto IA. Ten years results of the Canadian breast intensity modulated radiation therapy (IMRT) randomized controlled trial. Radiother Oncol 2016; 121: 414-9. doi: 10.1016/j.radonc.2016.08.021

32. De Langhe $\mathrm{S}$, Mulliez $\mathrm{T}$, Veldeman L, Remouchamps $\mathrm{V}$, van Greveling $\mathrm{A}$, Gilsoul $M$, et al. Factors modifying the risk for developing acute skin toxicity after whole-breast intensity modulated radiotherapy. BMC Cancer 2014; 14 711. doi: 10.1186/1471-2407-14-711

33. Lilla C, Ambrosone CB, Kropp S, Helmbold I, Schmezer P, von Fournier D, et al. Predictive factors for late normal tissue complications following radiotherapy for breast cancer. Breast Cancer Res Treat 2007; 106: 143-50. doi: $10.1007 /$ s10549-006-9480-9

34. Haviland JS, Owen JR, Dewar JA, Agrawal RK, Barrett J, Barrett-Lee PJ, et al The UK Standardisation of breast radiotherapy (START) trials of radiotherapy hypofractionation for treatment of early breast cancer: 10-year follow-up results of two randomised controlled trials. Lancet Oncol 2013; 14: 1086-94. doi: 10.1016/S1470-2045(13)70386-3

35. De Felice F, Ranalli T, Musio D, Lisi R, Rea F, Caiazzo R, et al. Relation between hypofractionated radiotherapy, toxicity and outcome in early breast cancer. Breast J 2017; 23: 563-8. doi: 10.1111/tbj.12792

36. Shaitelman SF, Schlembach PJ, Arzu I, Ballo M, Bloom ES, Buchholz D, et al. Acute and short-term toxic effects of conventionally fractionated vs hypofractionated whole-breast irradiation: a randomized clinical trial. JAMA Oncol 2015; 1: 931-41. doi: 10.1001/jamaoncol.2015.2666

37. Jagsi R, Griffith KA, Boike TP, Walker E, Nurushev T, Grills IS, et al. Differences in the acute toxic effects of breast radiotherapy by fractionation schedule: comparative analysis of physician-assessed and patient-reported outcomes in a large multicenter cohort. JAMA Oncol 2015; 1: 918-30. doi: 10.1001/ jamaoncol.2015.2590

38. Franco P, lorio GC, Bartoncini S, Airoldi M, De Sanctis C, Castellano I, et al. De-escalation of breast radiotherapy after conserving surgery in low-risk early breast cancer patients. Med Oncol 2018; 35: 62. doi: 10.1007/s12032018-1121-8

39. Jones B, Dale RG, Deehan C, Hopkins KI, Morgan DA. The role of biologically effective dose (BED) in clinical oncology. Clin Oncol (R Coll Radiol) 2001; 13: 71-81. doi: $10.1053 /$ clon.2001.9221

40. Yarnold J, Somaiah N, Bliss JM. Hypofractionated radiotherapy in early breast cancer: Clinical, dosimetric and radio-genomic issues. Breast 2015; 24 (Suppl 2): S108-13. doi: 10.1016/j.breast.2015.07.025 
41. Koulis TA, Phan T, Olivotto IA. Hypofractionated whole breast radiotherapy: current perspectives. Breast Cancer (Dove Med Press) 2015; 7: 363-70. doi: 10.2147/BCTT.S81710

42. Lazzari G, Terlizzi A, Della Vittoria Scarpati G, Perri F, De Chiara V, Turi B, et al. Predictive parameters in hypofractionated whole-breast 3D conformal radiotherapy according to the Ontario Canadian trial. Onco Targets Ther 2017; 10: 1835-42. doi: 10.2147/OTT.S127833

43. Marks LB, Bentzen SM, Deasy JO, Kong F-MS, Bradley JD, Vogelius IS, et al. Radiation dose-volume effects in the lung. Int J Radiat Oncol Biol Phys 2010; 76: S70-6. doi: 10.1016/j.jirobp.2009.06.091

44. Gagliardi G, Constine LS, Moiseenko V, Correa C, Pierce $\sqcup$, Allen AM, et al. Radiation dose-volume effects in the heart. Int J Radiat Oncol Biol Phys 2010; 76: S77-85. doi: 10.1016/j.jirobp.2009.04.093

45. Darby SC, Ewertz M, Hall P. Ischemic heart disease after breast cancer radiotherapy. N Engl J Med 2013; 368: 2527. doi: 10.1056/NEJMc1304601

46. Pierce $\sqcup$, Feng M, Griffith KA, Jagsi R, Boike T, Dryden D, et al. Recent time trends and predictors of heart dose from breast radiation therapy in a large quality consortium of radiation oncology practices. Int J Radiat Oncol 2017; 99: 1154-61. doi: 10.1016/j.jirobp.2017.07.022

47. Guan H, Dong YL, Ding $\sqcup$, Zhang ZC, Huang W, Liu CX, et al. Morphological factors and cardiac doses in whole breast radiation for left-sided breast cancer. Asian Pac J Cancer Prev 2015; 16: 2889-94. doi: 10.7314/ APJCP.2015.16.7.2889

48. Wernicke Ag, Heineman T, Sabbas A, Delamerced M, Chiu Y, Smith M, et al. Impact of a large breast separation on radiation dose delivery to the ipsilateral lung as result of respiratory motion quantified using free breathing and 4D CT-based planning in patients with locally advanced breast cancers: a potential for adverse clinical implications. J Cancer Res Ther 2013; 9: 154 doi: $10.4103 / 0973-1482.110368$

49. Grantzau T, Overgaard J. Risk of second non-breast cancer after radiotherapy for breast cancer: a systematic review and meta-analysis of 762,468 patients. Radiother Oncol 2015; 114: 56-65. doi: 10.1016/j. radonc.2014.10.004

50. Burt LM, Ying J, Poppe MM, Suneja G, Gaffney DK. Risk of secondary malignancies after radiation therapy for breast cancer: comprehensive results. Breast 2017; 35: 122-9. doi: 10.1016/j.breast.2017.07.004

51. Stovall M, Smith SA, Langholz BM, Boice JD, Shore RE, Andersson M, et al. Dose to the contralateral breast from radiotherapy and risk of second primary breast cancer in the WECARE study. Int J Radiat Oncol 2008; 72: 1021-30. doi: 10.1016/j.ijrobp.2008.02.040

52. Aznar MC, Duane FK, Darby SC, Wang Z, Taylor CW. Exposure of the lungs in breast cancer radiotherapy: a systematic review of lung doses published 2010-2015. Radiother Oncol 2018; 126: 148-54. doi: 10.1016/j. radonc.2017.11.022

53. Bhatnagar AK, Heron DE, Deutsch M, Brandner E, Wu A, Kalnicki S. Does breast size affect the scatter dose to the ipsilateral lung, heart, or contralateral breast in primary breast irradiation using intensity-modulated radiation therapy (IMRT)? Am J Clin Oncol 2006; 29: 80-4. doi: 10.1097/01. coc.0000198743.80991.15

54. Jin G-H, Chen L-X, Deng X-W, Liu X-W, Huang Y, Huang X-B. A comparative dosimetric study for treating left-sided breast cancer for small breast size using five different radiotherapy techniques: conventional tangential field, filed-in-filed, tangential-IMRT, multi-beam IMRT and VMAT. Radiat Oncol 2013; 8: 89. doi: 10.1186/1748-717X-8-89

55. Osa E-OO, DeWyngaert K, Roses D, Speyer J, Guth A, Axelrod D, et al. Prone Breast Intensity Modulated Radiation Therapy: 5-Year Results. Int J Radiat Oncol 2014; 89: 899-906. doi: 10.1016/j.jijrobp.2014.03.036

56. Ramella S, Trodella L, Ippolito E, Fiore M, Cellini F, Stimato G, et al. Wholebreast irradiation: a subgroup analysis of criteria to stratify for prone position treatment. Med Dosim 2012; 37: 186-91. doi: 10.1016/j.meddos.2011.06.010

57. Lymberis SC, deWyngaert JK, Parhar P, Chhabra AM, Fenton-Kerimian M Chang J, et al. Prospective assessment of optimal individual position (prone versus supine) for breast radiotherapy: volumetric and dosimetric correlations in 100 patients. Int J Radiat Oncol 2012; 84: 902-9. doi: 10.1016/j. ijrobp.2012.01.040
58. Fan L-L, Luo Y-K, Xu J-H, He L, Wang J, Du X. A dosimetry study precisely outlining the heart substructure of left breast cancer patients using intensitymodulated radiation therapy. J Appl Clin Med Phys 2014; 15: 4624. doi: 10.1120/jacmp.v15i5.4624

59. Würschmidt F, Stoltenberg S, Kretschmer M, Petersen C. Incidental dose to coronary arteries is higher in prone than in supine whole breast irradiation. Strahlenther Onkol 2014; 190: 563-8. doi: 10.1007/s00066-014-0606-4

60. Kirova YM, Hijal T, Campana F, Fournier-Bidoz N, Stilhart A, Dendale R, et al. Whole breast radiotherapy in the lateral decubitus position: a dosimetric and clinical solution to decrease the doses to the organs at risk (OAR). Radiother Oncol 2014; 110: 477-81. doi: 10.1016/j.radonc.2013.10.038

61. Bartlett FR, Colgan RM, Donovan EM, Carr K, Landeg S, Clements N, et al. Voluntary breath-hold technique for reducing heart dose in left breast radiotherapy. J Vis Exp 2014; 89. doi: 10.3791/51578

62. Mulliez T, Veldeman L, Vercauteren T, De Gersem W, Speleers B, Van Greveling A, et al. Reproducibility of deep inspiration breath hold for prone left-sided whole breast irradiation. Radiat Oncol 2015; 10: 9. doi: 10.1186/ s13014-014-0313-4

63. Bartlett FR, Colgan RM, Donovan EM, McNair HA, Carr K, Evans PM, et al. The UK HeartSpare Study (tage IB): randomised comparison of a voluntary breath-hold technique and prone radiotherapy after breast conserving surgery. Radiother Oncol 2015; 114: 66-72. doi: 10.1016/j.radonc.2014.11.018

64. Merino Lara TR, Fleury E, Mashouf S, Helou J, McCann C, Ruschin M, et al. Measurement of mean cardiac dose for various breast irradiation techniques and corresponding risk of major cardiovascular event. Front Oncol 2014; 4: 284. doi: 10.3389/fonc.2014.00284

65. Moran JM, Ben-David MA, Marsh RB, Balter JM, Griffith KA, Hayman JA et al. Accelerated partial breast irradiation: what is dosimetric effect of advanced technology approaches? Int J Radiat Oncol 2009; 75: 294-301. doi: 10.1016/j.jirobp.2009.03.043

66. Lettmaier S, Kreppner S, Lotter M, Walser M, Ott OJ, Fietkau R, et al. Radiation exposure of the heart, lung and skin by radiation therapy for breast cancer: a dosimetric comparison between partial breast irradiation using multicatheter brachytherapy and whole breast teletherapy. Radiother Oncol 2011; 100: 189-94. doi: 10.1016/j.radonc.2010.07.011

67. Mészáros N, Major T, Stelczer G, Zaka Z, Mózsa E, Pukancsik D, et al Implementation of image-guided intensity-modulated accelerated partial breast irradiation: three-year results of a phase II clinical study. Strahlenther Onkol 2017; 193: 70-9. doi: 10.1007/s00066-016-1074-9

68. Piroth MD, Petz D, Pinkawa M, Holy R, Eble MJ. Usefulness of a thermoplastic breast bra for breast cancer radiotherapy. Strahlenther Onkol 2016; 192: 609-16. doi: 10.1007/s00066-016-0981-0

69. Balaji K, Subramanian B, Yadav P, Anu Radha C, Ramasubramanian V. Radiation therapy for breast cancer: literature review. Med Dosim 2016; 41: 253-7. doi: 10.1016/j.meddos.2016.06.005

70. Arsene-Henry A, Fourquet A, Kirova YM. Evolution of radiation techniques in the treatment of breast cancer $(\mathrm{BC})$ patients: from 3D conformal radiotherapy (3D CRT) to intensity-modulated RT (IMRT) using helical tomotherapy (HT). Radiother Oncol 2017; 124: 333-4. doi: 10.1016/j.radonc.2017.07.002

71. Cozzi L, Lohr F, Fogliata A, Franceschini D, De Rose F, Filippi AR, et al. Critical appraisal of the role of volumetric modulated arc therapy in the radiation therapy management of breast cancer. Radiat Oncol 2017; 12: 1-12. doi: 10.1186/s13014-017-0935-4

72. Borca VC, Franco P, Catuzzo P, Migliaccio F, Zenone F, Aimonetto S, et al. Does TomoDirect 3DCRT represent a suitable option for post-operative whole breast irradiation? A hypothesis-generating pilot study. Radiat Oncol 2012; 7: 211. doi: 10.1186/1748-717X-7-211

73. Virén T, Heikkilä J, Myllyoja K, Koskela K, Lahtinen T, Seppälä J. Tangential volumetric modulated arc therapy technique for left-sided breast cancer radiotherapy. Radiat Oncol 2015; 10: 79. doi: 10.1186/s13014-015-0392-x

74. Zhao H, He M, Cheng G, Han D, Wu N, Shi D, et al. A comparative dosimetric study of left sided breast cancer after breast-conserving surgery treated with VMAT and IMRT. Radiat Oncol 2015; 10: 231. doi: 10.1186/s13014015-0531-4

75. Tan W, Wang X, Qiu D, Liu D, Jia S, Zeng F, et al. Dosimetric comparison of intensity-modulated radiotherapy plans, with or without anterior myocardial territory and left ventricle as organs at risk, in early-stage left-sided breast cancer patients. Int J Radiat Oncol Biol Phys 2011; 81: 1544-51. doi: 10.1016/j.ijrobp.2010.09.028 
76. Zhang L, Mei X, Chen X, Hu W, Hu S, Zhang Y, et al. Estimating cardiac substructures exposure from diverse radiotherapy techniques in treating left-sided breast cancer. Medicine (Baltimore) 2015; 94: e847. doi: 10.1097/ MD.0000000000000847

77. Haciislamoglu E, Colak F, Canyilmaz E, Dirican B, Gurdalli S, Yilmaz AH, et al. Dosimetric comparison of left-sided whole-breast irradiation with 3DCRT, forward-planned IMRT, inverse-planned IMRT, helical tomotherapy, and volumetric arc therapy. Phys Medica 2015; 31: 360-7. doi: 10.1016/j. ejmp.2015.02.005

78. Baycan D, Karacetin D, Balkanay AY, Barut Y. Field-in-field IMRT versus 3D-CRT of the breast. Cardiac vessels, ipsilateral lung, and contralateral breast absorbed doses in patients with left-sided lumpectomy: a dosimetric comparison. Jpn J Radiol 2012; 30: 819-23. doi: 10.1007/s11604-012-0126-z

79. Lohr F, El-Haddad M, Dobler B, Grau R, Wertz H-J, Kraus-Tiefenbacher U, et al. Potential effect of robust and simple IMRT approach for left-sided breast cancer on cardiac mortality. Int J Radiat Oncol Biol Phys 2009; 74: 73-80. doi: 10.1016/j.jijrobp.2008.07.018

80. Rudat V, Nour A, Ghaida SA, Alaradi A. Impact of hypofractionation and tangential beam IMRT on the acute skin reaction in adjuvant breast cancer radiotherapy. Radiat Oncol 2016; 11: 100. doi: 10.1186/s13014-016-0674-y

81. Ciammella P, Podgornii A, Galeandro M, Micera R, Ramundo D, Palmieri $T$, et al. Toxicity and cosmetic outcome of hypofractionated whole-breast radiotherapy: predictive clinical and dosimetric factors. Radiat Oncol 2014; 9: 97. doi: 10.1186/1748-717X-9-97

82. Lee E, Takita C, Wright JL, Reis IM, Zhao W, Nelson OL, et al. Characterization of risk factors for adjuvant radiotherapy-associated pain in a tri-racial/ ethnic breast cancer population. Pain 2016; 157: 1122-31. doi: 10.1097/j. pain. 000000000000489

83. Mak KS, Chen Y-H, Catalano PJ, Punglia RS, Wong JS, Truong L, et al. Dosimetric inhomogeneity predicts for long-term breast pain after breastconserving therapy. Int J Radiat Oncol Biol Phys 2014; 93: 1087-95. doi: 10.1016/j.jijrobp.2014.05.021

84. Stimato G, Ippolito E, Silipigni S, Venanzio C Di, Rinaldi CG, Gaudino D, et al. A new three-dimensional conformal radiotherapy (3DCRT) technique for large breast and/or high body mass index patients: evaluation of a novel fields assessment aimed to reduce extra-target-tissue irradiation. $\mathrm{Br}$ Radiol 2016; 89: 20160039. doi: 10.1259/bjr.20160039

85. Mulliez T, Speleers B, Madani I, De Gersem W, Veldeman L, De Neve W. Whole breast radiotherapy in prone and supine position: is there a place for multi-beam IMRT? Radiat Oncol 2013; 8: 151. doi: 10.1186/1748-717X8-151

86. Goldsmith C, Haviland J, Tsang Y, Sydenham M, Yarnold J. Large breast size as a risk factor for late adverse effects of breast radiotherapy: is residual dose inhomogeneity, despite 3D treatment planning and delivery, the main explanation? Radiother Oncol 2011; 100: 236-40. doi: 10.1016/j. radonc.2010.12.012

87. Juneja P, Bonora M, Haviland JS, Harris E, Evans P, Somaiah N. Does breast composition influence late adverse effects in breast radiotherapy? Breast 2016; 26: 25-30. doi: 10.1016/j.breast.2015.12.004

88. Kirby AM, Evans PM, Donovan EM, Convery HM, Haviland JS, Yarnold JR. Prone versus supine positioning for whole and partial-breast radiotherapy: a comparison of non-target tissue dosimetry. Radiother Oncol 2010; 96: 178-84. doi: 10.1016/j.radonc.2010.05.014

89. Aznar MC, Korreman S-S, Pedersen AN, Persson GF, Josipovic M, Specht L Evaluation of dose to cardiac structures during breast irradiation. Br J Radiol 2011; 84: 743-6. doi: 10.1259/bjr/12497075

90. van den Bogaard VAB, Ta BDP, van der Schaaf A, Bouma AB, Middag AMH, Bantema-Joppe EJ, et al. Validation and modification of a prediction model for acute cardiac events in patients with breast cancer treated with radiotherapy based on three-dimensional dose distributions to cardiac substructures. J Clin Oncol 2017 35: 1171-8. doi: 10.1200/JCO.2016.69.8480

91. Haciislamoglu E, Colak F, Canyilmaz E, Zengin AY, Yilmaz AH, Yoney A, et al. The choice of multi-beam IMRT for whole breast radiotherapy in early-stage right breast cancer. Springerplus 2016; 5: 688. doi: 10.1186/s40064-0162314-2

92. Coles CE, Griffin CL, Kirby AM, Titley J, Agrawal RK, Alhasso A, et al. Partialbreast radiotherapy after breast conservation surgery for patients with early breast cancer (UK IMPORT LOW trial): 5-year results from a multicentre, randomised, controlled, phase 3, non-inferiority trial. Lancet 2017; 390: 1048-60. doi: 10.1016/S0140-6736(17)31145-5
93. Strnad V, Ott OJ, Hildebrandt G, Kauer-Dorner D, Knauerhase H, Major T, et al. 5-year results of accelerated partial breast irradiation using sole interstitial multicatheter brachytherapy versus whole-breast irradiation with boost after breast-conserving surgery for low-risk invasive and in-situ carcinoma of the female breast: a randomised, phase 3, non-inferiority trial. Lancet 2016; 387: 229-38. doi: 10.1016/S0140-6736(15)00471-7

94. Ott OJ, Strnad V, Hildebrandt G, Kauer-Dorner D, Knauerhase H, Major T, et al. GEC-ESTRO multicenter phase 3-trial: Accelerated partial breast irradiation with interstitial multicatheter brachytherapy versus external beam whole breast irradiation: Early toxicity and patient compliance. Radiother Oncol 2016; 120: 119-23. doi: 10.1016/j.radonc.2016.06.0 